\title{
A EDUCAÇÃO ROMANA \\ E O DESTINO DO LATIM PENINSULAR
}

Afrânio da Silva Garcia (UERJ)

\section{Introdução}

O objetivo deste trabalho é o de apresentar, da maneira mais completa e clara possível, o sistema de educação romano e como ele influiu no destino que teve o latim na Península Ibérica.

Para fins de clareza e organização, dividi meu trabalho em três partes: na primeira, procurei dar uma visão geral do que foi a educação romana, suas partes constitutivas e os objetivos a que se propunha; na segunda, eu faço uma análise de como essa educação se processou na Hispânia romana., de que maneira ela se enquadra na Idade Média latina e quais as suas características que mais influência tiveram na Idade Média; por último, eu exponho as conclusões a que cheguei com meus estudos.

Quanto à validade de meu trabalho, acho-o de enorme importância para o avanço da pesquisa e dos estudos em meu país, visto que somos, de certa maneira, devido à nossa língua e à nossa origem portuguesa, continuadores da tradição latina. Por outro lado, o fato de termos tão poucos trabalhos disponíveis nessa área, como foi atestado pelo fato de eu ter sido forçado a basear minha pesquisa, principalmente, em trabalhos de autores estrangeiros, quer no original, quer traduzidos, confere ao meu trabalho não apenas validade, como a necessária originalidade.

\section{A educação romana}

A educação romana variou bastante no curso da história de Roma. O período que mais nos interessa é a época "imperial", que compreende os séculos I e II depois de Cristo, pois foi durante esse período que a educação romana mais se efetivou na Península Ibérica, moldando, desse modo, a posterior educação romano-cristã das "escolas conventuais". Segundo Messer (apud CASSANI, 1952) "esta época se caracteriza pela perda do caráter nacional e cívico da e- 
ducação, o domínio do cosmopolitismo e do individualismo, o sentido egoísta, utilitário e lucrativo, o refinamento e o virtuosismo oratório".

A educação romana distinguia os três tipos básicos de educação:

1) Primária ou elementar;

2) Secundária;

3) Superior e profissional.

Como um todo, no entanto, fundava-se ela, principalmente ao tempo da civilização hispano-gótica, nas sete "artes liberales": a gramática, a retórica e a dialética, por um lado, e a aritmética, a geometria, a música e a astronomia, que constituíam as chamadas artes matemáticas, por outro. Artes indicava algo bem distinto do significado moderno de arte; significava "conjuntos de regras que ensinam a fazer corretamente alguma coisa" (algo como o "know-how"). $\mathrm{Li}$ berais indicava serem artes dignas de um homem livre, ao contrario das "artes mechanicae", que servem para ganhar dinheiro e são mais próprias de um escravo.

Dentre as artes, estudava-se de maneira muito mais ampla e profunda as três primeiras: a gramática, a retórica e a dialética, chamadas de "trivium" a partir do século IX, do que as do "quadrivium" ou artes matemáticas: a aritmética, a geometria, a música e a astronomia. A mais estudada de todas era, porém, a gramática, que compreendia, de acordo com Quintiliano (apud CURTIUS, 1979): "recte loquendi scientiam et poetarum enarrationem" (uso correto da língua e explicação dos poetas). Só muito mais tarde é que as palavras gramática e literatura (do grego gramma e sua tradução latina littera, ambas significando letra) passam a designar os conceitos distintos que hoje lhes atribuímos.

A educação romana, no entanto, não se limitava ao ensino das sete artes liberais. Tanto em Roma como na Espanha Romana, ensinava-se ainda: filosofia, medicina, direito, engenharia e arquitetura, artesanato, pintura, escultura, dança, etc., como nos dão prova as Etimologías de Santo Isidoro (livros IV, V, IX e XI a XX), assim como as esplêndidas edificações que deixaram. Não obstante, as $a r$ - 
tes representarão, para a Idade Média, a ordem fundamental do espírito até o século XII.

\subsection{O ensino elementar}

$\mathrm{O}$ infante, que antes do período imperial era atentamente dirigido e vigiado pelos pais, passa a ser negligenciado por eles, entregues que estavam aos novos prazeres e ocupações, e confiados a mãos servis, muitas vezes de indivíduos ineptos ou nocivos. Muitos autores combatiam essa despreocupação prejudicial dos pais, aconselhando-os a dedicar atenção pessoal ao infante ou a serem mais cuidadosos na escolha do preceptor.

Entre os seis e sete anos, passavam as crianças a receber o primeiro aprendizado formal, em escolas públicas ou particulares, sendo que o ensino público era preferido mesmo pelos romanos mais abastados. A escola primária romana era mista, acorrendo a ela, indistintamente, meninos e meninas. Quanto aos professores, o "pedagogus" ou "ludi magister", eram geralmente de baixa origem, muitas vezes escravos, e muito mal pagos, o que os obrigava a desempenhar outras tarefas, como a de escrevente, para poder subsistir. Por estas razões, os alunos os menosprezavam e não lhes respeitavam, devendo o pobre pedagogo usar de castigos físicos para obrigá-los a cumprir as tarefas. O açoite estava na ordem do dia, constituindo verdadeira tortura para os alunos e meio de desafogar o espírito malsão de certos professores.

A carência de meios dos pedagogos refletia a carência dos meios materiais de ensino. Não havia qualquer tipo de edificação escolar. Os mestres davam suas aulas onde lhes permitiam seus meios, às vezes num simples cubículo. A esta pobreza de local de estudo somava-se a pobreza dos utensílios de ensino: um ábaco, dois ou três sólidos para as aulas de geometria e pouca coisa mais. As classes tomavam todo o dia, com um breve descanso para almoçar, e eram suspensas no verão, para as "nundinas" e as "quintratus".

Com meios tão parcos e preparação tão deficiente, que podiam ensinar tais mestres? Muito pouco: somente noções elementares de leitura, escritura e cálculo. Começava-se por ensinar a ordem das letras e logo, por meio de memorizações, a maioria das vezes à custa 
de açoite, obrigava-se ao aluno a realização de um novo esforço: agrupá-las em sílabas e, posteriormente, em palavras. $\mathrm{O}$ ensino de escritura era ainda pior: a mão do mestre levava a do aluno e, logo em seguida, este devia reproduzir os traços que lhe punham à frente. $\mathrm{O}$ mesmo acontecia com a aritmética: consistia num monótono escutar e repetir e breve era cobrado do aluno realizar as mais complicadas operações. Esse sistema de ensino, com seus meios precários, em que os alunos eram forçados a repetir ate o esgotamento coisas que os enfastiavam, era muito pouco eficiente. Daí o grande numero de analfabetos existentes então. Só mesmo os alunos muito bem dotados podiam superar a escola elementar de maneira produtiva e pegar apego aos estudos.

Aproximadamente o mesmo tipo de ensino era ministrado aos filhos de escravos e aos habitantes das províncias. O motivo principal da implantação de escolas romanas na província era o de garantir a fidelidade dos cidadãos mais importantes e, ao mesmo tempo, deslumbrá-los com o aparato com que tratava seus filhos, mas havia também o intuito de instruir a população, para que se formasse nela uma consciência de serem parte do Império Romano, de modo a garantir uma base firme para a administração romana. Não podemos concordar com Plutarco (apud CASSANI, 1952), quando diz que os romanos fingiam instruir os jovens espanhóis, mas na verdade "os tomavam como reféns", pois a educação, juntamente com os jogos, o teatro, as estradas, etc., fazia parte do esforço romano de dominação pacífica, em suma, de romanização das regiões conquistadas.

\subsection{O ensino secundário ou do gramático}

Concluí do o trabalho do "ludi magister", numa idade aproximada de doze anos, passavam os meninos, já com certa preparação, a receber a instrução do "gramaticus". Tal ensino, inspirado nos moldes gregos, havia começado no século II antes de Cristo. Seu objetivo era capacitar os jovens romanos a administrar e governar sem inconveniente as novas terras conquistadas. Por isso mesmo, era ele privilégio da classe dominante, de modo a evitar que esta perdesse sua hegemonia e, consequentemente, a da Cidade Eterna. Para esse tipo de ensino, os romanos aproveitaram-se inicialmente dos emigrantes políticos da Ásia Menor ou do Egito. Os professores roma- 
nos herdaram destes seu uso; daí, a retórica continuar sempre a ser ensinada em grego, enquanto a gramática era ensinada em grego e latim.

Nas escolas desse tipo, ensinava-se aproximadamente as matérias conhecidas com o nome de "trivium" e "quadrivium": gramática, retórica e dialética; aritmética, geometria, música e astronomi$a$. É importante notar, entretanto, que a retórica gozava de uma posição privilegiada dentro desse contexto, já que tanto Cassani quanto Curtius dedicam a ela capítulos separados: o primeiro dedica um capítulo a Literatura e Educação e outro a Retórica, enquanto o segundo separa $O$ ensino secundário ou do gramático do Ensino de retórica. Nesta seção, abordaremos os elementos constitutivos da retórica, conforme os apresenta Isidoro, na parte referente ao ensino secundário, deixando para apresentar as características das classes de retórica para a parte referente ao ensino superior e de ofícios.

O gramático devia dedicar o máximo de seus esforços a desenvolver no aluno o maior desembaraço possível no falar e escre$v e r$, mediante o estudo tenaz dos textos dos autores. A princípio, os textos eram especialmente Homero, os trágicos, os cômicos, os líricos e as obras de Esopo, ao passo que os textos latinos se limitavam a Lívio Andronico, Ênio e Terêncio, mas logo a situação se modificou e os autores latinos, principalmente depois da reação de Cecílio Epirota, passaram a ser privilegiados: Virgílio e Cícero, inicialmente, e depois Sêneca, Horácio, Ovídio, Lucano e outros.

Os gramáticos eram mais bem vistos que os mestres elementares, mas nem por isso eram muito melhor pagos: recebiam menos do que um cocheiro bem sucedido. Os métodos em que se baseavam os gramáticos estavam apoiados, como quase toda a instrução romana, na memória. Consistiam na repetição de textos, seguida de seu exame detalhado, como segue:

a) Ditado do texto.

b) Repetição memorizada.

c) Imitação. Tradução de verso em prosa ou vice-versa.

d) Análise das palavras. 
e) Composição (Geralmente explicação de uma máxima ou elogio de uma boa ação).

Sem dúvida alguma, esse tipo de ensino dependia muito da preparação do gramático, que resultava muitas vezes deficiente. Estudaremos agora a constituição das matérias básicas desse ensino, o chamado trívio: gramática, retórica e dialética, deixando de lado as matérias do quadrívio, que pouco nos interessam para esse trabalho.

\subsubsection{A gramática}

Segundo Isidoro, o ensino de gramática era "a origem e fundamento das disciplinas liberais". O princípio do ensino da gramática seria o ensino das letras comuns, ou seja, ler e escrever. Tal ensino era feito de uma maneira bem pouco científica, com narrações acerca das origens das letras e a inclusão do estudo das letras "místicas". Ao mesmo tempo, é ensinada a correlação de determinadas letras com números, como em I e X. Ele discorre também acerca do nome, da figura, do poder, da ordem e do acento das letras.

À parte essas informações aleatórias, ele faz também distinção entre vogais, semivogais e mudas. É importante notar que, embora utilizassem a mesma denominação que hoje em dia se usa, o significado de semivogais e mudas era bastante diferente: semivogais eram aquelas letras cujo nome começava pela letra $e$, como $r, f, m$., $n$, $l$ e $s$, enquanto mudas são aquelas letras cujo nome acaba com a letra $e$, como $b, c, d, g$ etc. As semivogais e mudas formavam as consoantes, cuja definição, assim como a das vogais, era a mesma que a atual.

As partes da oração eram divididas em oito partes: nome, verbo, pronome, advérbio, particípio, conjunção, preposição e interjeição. Isidoro concorda com Aristóteles em que a oração se divide em duas partes principais: nome e verbo, já que as demais estariam a estas relacionadas (uma relação bastante semelhante a atual relação entre determinante e determinado). O nome se distinguia, no entanto, da noção de determinado, por incluir o substantivo e o adjetivo, chamado epíteto. $\mathrm{O}$ nome era dividido em inúmeras categorias, entre as quais principais (primitivos) e derivados, sinônimos e homônimos, relativos (quando partes de um contraste) e várias outras, de acordo 
com o significado ou o número de casos possíveis ou a sua ascendência. Distinguia o nome as categorias de comparação (positivo, comparativo e superlativo), gênero (masculino, feminino, neutro, comum e epiceno), número (singular e plural) e casos.

$\mathrm{O}$ pronome se dividia em determinado (pessoal), indeterminado (indefinido) e menos que determinado (possessivo ou demonstrativo), em primitivo ou derivado (como qualquer). $\mathrm{O}$ demonstrativo, quando adjetivo, chama-se artigo.

O verbo tinha tempo: passado, presente e futuro; forma: meditativa (mostra desejo ou intenção), incoativa (progressivo) e frequentativa; modo: indicativo, imperativo, optativo (hipotético), conjuntivo (para orações subordinadas) e infinitivo; conjugação e gênero (voz): ativo, passivo, neutro (como em jazer), comum (recíproco) e depoente. Isidoro distingue o verbo dos gramáticos do dos retóricos: oração, fala.

O advérbio é definido como algo que se une "ad verbum" para fazer sentido. O particípio é definido como algo que toma parte nas condições do nome (gênero e casos) e do verbo (tempo e significado). A conjunção é aquilo que conjunge os conceitos ou orações. Podem ser copulativas (aditivas), disjuntivas (alternativas), subjuntivas (integrantes), expletivas (que completam a coisa proposta, como se não... ao menos), comuns (as que podem ser mudadas de posição), causais e racionais (definição confusa, exemplificada por como). As preposições podem ser de acusativo, de ablativo ou prefixais (como em deduzir). As interjeições tinham a mesma definição que hoje.

Depois, Isidoro discorre acerca da parte fônica da língua e da métrica. A sílaba era dividida em breve, longa e comum (que pode ser longa ou breve). A métrica era muito bem estudada. Distinguiamse vinte e quatro diferentes tipos de pés, de acordo com o número de sílabas (de dois a seis) e a relação entre "arsis" (a parte acentuada) e "thesis" (a parte não acentuada). Os metros, por sua vez, recebiam várias classificações, conforme os pés, os inventores, quem mais usava, a matéria de que tratavam ou as situações a que se aplicavam. Estudava-se também o que era poesia e suas partes. Os acentos compreendiam os atuais, os de quantidade, os de aspiração e a diástole, que era o oposto do hífen. A pontuação era feita pela posição do ponto: vírgula (o ponto ficava abaixo da linha), cólon ou dois pontos 
(o ponto ficava no meio da linha), e ponto mesmo (o ponto ficava acima da linha). Estudavam-se as siglas das sentenças (atuais sinais tipográficos), em número de vinte e seis, além de outras siglas: vulgares, jurídicas, militares e de cartas. Isidoro fala do uso de sinais com os dedos e logo passa a ortografia, citando 30 exemplos, sem nenhuma metodologia de escolha, puramente ao acaso.

Em seguida, ele fala de relações de significado. A analogia era baseada no conceito de semelhança, diferenciada da anomalia (semelhança de sons entre palavras díspares, como lupus e lepus). A etimologia consistia na maioria das vezes, na verdade, do que hoje se chama etimologia popular. A glosa seria a explicação de uma coisa por seu sinônimo, enquanto a diferença era a explicação pelo contrário.

Os vícios são: barbarismo (erro de pronúncia), solecismo (erro de construção), cacófato, pleonasmo; perissologia (pleonasmo exagerado), macrologia (redundância), tautologia, elipse, cacossíndeto e anfibologia (ambiguidade).

Os metaplasmos ou transformações se deviam à licença poética e são: prótese, paragoge, ectase, epissinalefa, eclipse, "antítesis" (troca de letras) e metátese.

A gramática romana era abundante em figuras do discurso, divididas em esquemas, figuras de construção, e tropos, figuras de palavras. As figuras de gramática, importantes para a explicação dos poetas, e as figuras de retórica distribuíam-se, sem muito rigor, numa ou noutra categoria. Curtius diz: "A tropologia não possui uma sistemática satisfatória". Essa discrepância deve-se, bem como a "variação das enumerações e característica das figuras", à diversidade de opiniões das escolas.

Isidoro classifica os seguintes esquemas: prolepse ou inversão, zeugma (um verbo para várias orações), hipozeuxis (um verbo por oração), silepse (ausência de concordância), anadiplose (começo de verso pela palavra final do anterior), anáfora (repetição no início de vários versos), epanáfora (repetição no início e meio do verso), epizeuxis (repetição seguida), epanalepse (repetição no início e fim de verso), paranomásia (palavras de som semelhante e sentido diverso), "squesis onomaton" (palavras associadas), "paromeon" (alitera- 
ção), "homoteleuton" (mesma terminação), "hemeoptoton" e "polyptoton" (figuras casuais), "hirmos" (oração intercalada por outra), polissíndeto e assíndeto, antítese e hipálage.

Os tropos eram: metáfora, catacrese, metalepse (o antecedente pelo consequente e vice-versa), metonímia e sinédoque; antonomásia (dizer por rodeios) e perífrase; epíteto, onomatopeia; hipérbato (dividido em: anástrofe, "histeron proteron", parênteses, "tmesis" e "synthesis"); hipérbole, alegoria, ironia, antífrase, enigma, eufemismo, paremia (uso de provérbios), sarcasmo, "homeosis" (subdividido em ícone, parábola e paradigma) e símile.

Isidoro define a prosa e a fábula, dividindo esta em esópicas (em que não há homens) e libísticas (onde os homens interagem com os animais). A história, por sua vez, é definida como a narração do acontecido. Os primeiros historiadores são Moisés, Dares da Frígia, Heródoto e Ferecides. A utilidade da história é a de esclarecer o presente pelo passado.

\subsubsection{A retórica}

Retórica é a arte da oração, a ciência de bem falar nos assuntos civis, de forma a persuadir pela eloquência. Constituiu ela um ideal de vida, de beleza, uma coluna básica da cultura antiga. Mas a retórica que penetrara a Hispânia, ao tempo do Imperium, já tinha assumido outra feição. Como diz Curtius:

A queda da república influiu na eloquência romana, no mesmo sentido que o domínio macedônio, e depois romano, na grega. Sob o principado de Augusto e sucessores, o discurso político teve de emudecer. A retórica torna-se eloquência escolar. Promove exercícios (declamationes) sobre processos forenses simulados. Tácito estudou o declínio da retórica em seu Dialogus de Oratoribus. Mas já de há muito se abrira à retórica um novo campo, com a sua passagem para a poesia romana. Isso foi obra de Ovídio. Ele "tomava um tema para versar ou, como acontecia nas declamações, mandar que outra pessoa falasse. (. . .) Aqui a retórica entra a serviço de uma poesia amena e espirituosa, e eleva com a sua graça o encanto da matéria interessante. Mas a retórica também consegue tirar o maior efeito de um conteúdo trágico, pela acumulação da tragédia, tensão, gradação e exagero. Aparece, depois, o estilo patético, representado nos tempos neronianos pelas tragédias de Sêneca e pela epopeia de Lucano... 
Afora esse uso literário da retórica, transforma-se esta em pura eloquência escolar.

A retórica antiga compreendia cinco partes: invenção, disposição, elocução, memória e ação, sendo as últimas duas de pouca monta. Dentre as outras, a mais importante era a disposição, que se dividia em exórdio, narração, argumentação, refutação e conclusão. A perda da liberdade na época imperial levou a perda da importância da refutação, a qual nem é citada por Isidoro.

Havia três gêneros de causas ou de eloquência: o discurso forense ou judicial, o deliberativo, que dizia o que se deve ou não fazer, e o laudatório ou demonstrativo, também usado para censura. Com o Império, desaparece o discurso forense, reduzido a simples exercício escolar, e desenvolve-se enormemente o discurso laudatório ou pomposo. Nas argumentações, os oradores costumavam usar uma série de argumentos pré-fixados pela tradição, apropriados à descrição, ao desenvolvimento e a variação: os topos ou "loci communes". Esses topos foram tão importantes que geraram uma disciplina: a tópica.

Além dos topos, usavam-se muitos recursos para persuadir a audiência: as sentenças e exemplos, comuns à retórica e à gramática; a linguagem, que devia ser isenta de vícios, correta e com bom uso das figuras de palavras, como anadiplose, antítese, etc., e figuras de sentenças, como paradoxo, ironia, etc.; e o estilo, que devia usar de etopeia (personificação histriônica), grandeza ou moderação (conforme a causa).

\subsubsection{A dialética}

A dialética ou lógica é uma divisão da filosofia. A filosofia é o conhecimento das coisas humanas e divinas. Divide-se em física, que estuda as coisas naturais e abrange as disciplinas do quadrívio, em ética, que estuda a moral, e em lógica, que estuda as causas das coisas, o que e racional. O estudo da dialética romano baseava-se na "Isagoge" de Porfírio: "O homem é um animal racional, mortal, terreno, bípede e capaz de rir"; e nas "Categorias" de Aristóteles: qualidade, quantidade, substância, relação, tempo, hábito, atividade e passividade. Os silogismos (argumentações) dialéticos eram de vá- 
rios tipos, de acordo com os critérios de universal versus particular e afirmação versus negação. As definições das coisas eram feitas a partir de descrição, comparação ou associação. Os tópicos eram divididos em intrínsecos, extrínsecos e afeitos (relacionados) à causa. Isidoro apresenta, ainda, uma excelente descrição dos opostos, em que apresenta a diferença, atualmente vigente na linguística, que divide os opostos em graduáveis e não graduáveis; temos, então, os contrários, como branco e negro, os relativos, como único e duplo, a privação, como cegueira e visão, e a negação, como "Sócrates lê" e "Sócrates não lê".

A partir do século XII, o aumento de prestígio da dialética ira ser responsável pela derrocada dos autores didáticos, junto a outros fatores.

\subsection{O ensino de retórica e o ensino superior}

O orador de Catão, "vir bonus et discendi peritus" (o homem bom e perito na arte de falar), deixa de existir no Império Romano. A eloquência, privada de sua capacidade de ação, torna-se uma coisa vazia, uma simples arte do palavrório. Suetônio (apud CASSANI, 1952) diz: "chega a um ponto que faz temer pela sorte de um povo que deixa o melhor de sua juventude se alimentar com tão mesquinho conteúdo intelectual", preparando-o, como disse Sêneca, "non vitae sed scholae".

Havia um desprezo geral por parte dos escritores de importância contra a falsa posição dos professores de retórica que, mesmo quando bem intencionados, equivocavam o caminho ao utilizar um método que conduzia ao contrario do que pregavam.

Os professores de retórica, regiamente pagos em muitos casos, mal pagos em outros, foram um elemento característico de sua época, exercendo muita influência sobre as gerações romanas, em classes muito numerosas. Se a influência foi boa ou má, é outro caso: embora a maioria se pronuncie contra, há quem ache que os exercícios monótonos desenvolviam as condições de atenção e raciocínio do aluno. 
Ademais, a eloquência era considerada uma necessidade para o homem culto e, especialmente, para chegar a melhores posições e escalar socialmente.

$\mathrm{O}$ estudo superior na Roma Imperial era dividido, basicamente, no estudo dos "autores" e no exercício prático das matérias. A importância dos autores, aliás, é uma das principais características da educação romana, como um todo. Ainda não existia uma ciência ou disciplina, na acepção moderna do termo.

O que existia era um estudo dos grandes autores e sábios desta ou daquela matéria; a dialética era o estudo da "Isagoge" de Porfírio e das "Categorias" de Aristóteles; a gramática era o estudo da "ars minor" e "ars maior" de Donato, da Institutio Grammatica de Prisciano e, a partir do século I, da parte da Institutio Oratoria de Quintiliano referente à gramática, além de uma infinidade de sentenças e exemplos de outros autores; a retórica consistia, basicamente, na Retórica a Herênio, de autor desconhecido, no Da Invenção de Cícero e na Institutio Oratoria de Quintiliano, além de máximas e exemplos tomados a vários autores; a medicina fundava-se em Galeno e Hipócrates; a história é a história de Heródoto ou de Orósio ou a da Bíblia, e assim por diante.

\section{O destino do latim peninsular}

Os romanos chegaram a Península Ibérica no século III a.C., durante a guerra com Cartago, guerra que se prolongou de 264 a 146 a.C. A anexação da Hispânia como província, porem, só se deu em 197 a.C.

A dominação de Roma continuou até 395 d.C. , data que marca o fim do Império Romano do Ocidente e começo da Idade Média, com a queda de Roma, invadida pelos bárbaros germânicos. A Hispânia, no entanto, mantém-se como província romana independente até a chegada dos alanos, asdingos, silingos e quadossuevos em 409.

A última província hispânica a ser anexada foi a Lusitânia, em 25 a.C. Os cantabros, porém, nunca foram dominados e permanecem até hoje como um povo à parte: os bascos. Devido às diferenças peculiares a cada região, os romanos dividiram a Hispânia em 
três regiões ou províncias: Bética, a de dominação mais antiga, a mais romanizada e a mais importante; Lusitânia, a segunda em importância, mas bem menos romanizada; e Tarraconense, a mais atrasada, submetida a invasões e revoltas constantes.

Os romanos, grandes administradores que eram, trataram logo de procurar romanizar, isto e, adaptar à sua cultura e civilização, os povos vencidos. Para tanto, valiam-se principalmente da educação, das artes e da diversão, sendo a educação o fator mais importante da romanização.

A educação romana foi amplamente difundida na Península Ibérica, não só na Bética, como na Lusitânia e na Tarraconense, em todas as suas formas: elementar, secundária e superior. Disso dão provas as "Lex Metalli Vipascensis", que atestam a existência de "ludi magistri" em Portugal já no século I a. C., e também quatro inscrições procedentes de Écija, Abdera e Tarragona (duas inscrições), sobre pedagogos; as inscrições de Astorga, Sagunto, Clunia e Tricio, sobre a atividade de certos "gramáticos"; e as inscrições de Cádiz e Collipot a respeito de "rhetores".

Além dessas provas documentais do vulto da educação romana, temos ainda a evidência da importância dessa educação no grande número de escritores hispânicos talentosos: Sêneca, o Reitor; Sêneca, o Filósofo; Marcial; o grande Lucano; Quintiliano, o mestre de retórica; Pompônio e Mela. Também servem para atestar a importância da Hispânia os imperadores romanos nascidos na Hispânia: Trajano, Adriano e Marcos Aurélio.

A organização da educação romana, centrada na gramática e na retórica e, bem menos, na dialética, foi importantíssima para o destino do latim na Península Ibérica. Como todas essas três "artes" são vinculadas à fala, à habilidade no falar, o estudante de qualquer uma delas estava sempre, de uma maneira ou outra, estudando latim. Por outro lado, o estudo dos autores, em todas as disciplinas, reforçava ainda mais esse aprendizado eminentemente linguístico. Não é à toa que a Hispânia produziu um autor do porte de Quintiliano, cujo Institutio Oratoria constitui o modelo da retórica, não só da época imperial, como de toda a Idade Média. 
O latim que chegou aos hispânicos influiu, também, no destino do latim peninsular. Como a Hispânia foi a terceira região a ser anexada ao Império Romano, em 197 a.C., apenas cerca de 40 anos após a Sicília e a Córsega e Sardenha, cerca de 100 anos antes da Gália, recebeu um latim vulgar bem menos modificado do que o das regiões conquistadas posteriormente. Essa seria uma das causas principais de ser o português, hoje em dia, juntamente com o sardo, as duas línguas que mais semelhança guardam com o latim.

Outra causa dessa extraordinária semelhança entre o latim vulgar ("sermo vulgaris") e o português, que faz com que praticamente não se distingam as tendências de evolução do latim vulgar daquelas do português, é o fato de, tendo a romanização se processado por toda a Península Ibérica, após a separação entre Portugal e Espanha, esta passa a funcionar como um estado-tampão, profundamente romanizado, contra a influência de transformação linguística do resto da Europa e da África.

Não menos importante, para o destino que teve o latim na Península Ibérica, foi o fato de os germanos, ao invés de imporem sua cultura aos vencidos, adaptarem-se a esta. Curtius diz: "Logo que tomavam pé, os seus reis cercavam-se de mestres de retórica, juristas e poetas", e depois, "A invasão dos bárbaros não mudou os traços essenciais da vida espiritual no espaço do Mediterrâneo ocidental". Por isso, pode-se dizer que, a partir de 586, com a conversão de Recaredo por Isidoro de Sevilha, o Império Romano volta a existir, não mais centrado na Itália, mas na Espanha romano-goda, e continuará a existir, como centro irradiador da cultura latina, de sua língua e de sua educação, até a invasão dos árabes, em 711. Mas a cultura lati$n a$, difundida por Isidoro de Sevilha, continuará a ser a tônica dominante de toda a Idade Média, daí a tese moderna de Idade Média latina.

\section{Conclusão}

Pelo que vimos, a educação romana desempenhou um papel de profunda importância no desenvolvimento que sofreu o latim na Península Ibérica. Por ser um aprendizado eminentemente linguístico, ajudou a romanizar a Península Ibérica, assim como ajudou a dar 
uma diretriz normativa uniforme, devido à importância primordial da gramática; por ter sido difundido nos mais remotos rincões do país, impediu, de certo modo, uma dialetação exagerada; por terem mantido suas características, a despeito das influências externas, ajudaram na conservação da língua latina na forma mais pura em que ela sobrevive, como a "última flor do Lácio, inculta e bela": o português.

\section{BIBLIOGRAFIA}

ALTON, E. H. Ovid in the Medieval schoolroom. In: Proceedings of the classical association. Cambridge, 1937, p. 32-35

CÂMARA JUNIOR, J. M. História e estrutura da língua portugue$s a$. 3. ed. Rio de Janeiro: Padrão, 1979, p.7-25

CASSANI, J. L. Aportes al estudio del processo de la romanización de Espana. Las instituciones educativas. In: Cuadernos de historia de España. Buenos Aires, 1952, p. 50-70

COUTINHO, Ismael de Lima. Pontos de gramática histórica. 7. ed. rev. Rio de Janeiro: Ao Livro Técnico, 1976, p. 29-52

CUNHA, Celso \& CARDOSO, Wilton. Estilística e gramática histórica. Rio de Janeiro: Tempo Brasileiro, 1978, p. 47-56

CURTIUS, Ernest Robert. Literatura europeia e Idade Média latina. 2. ed. Brasília: Instituto Nacional do Livro, 1979, p. 1-81

HAUSER, Arnold. História social da literatura e da arte. 4. ed. São Paulo: Mestre Jou, 1982, vol. I, p. 181-226

SEVILLA, San Isidoro de. Etimologías. Trad. Luis Cortés y Gongora. Madrid: Editorial Católica, 1951, p. 1-79 (Introduccion general) e 5-73 (Libros I e II). 